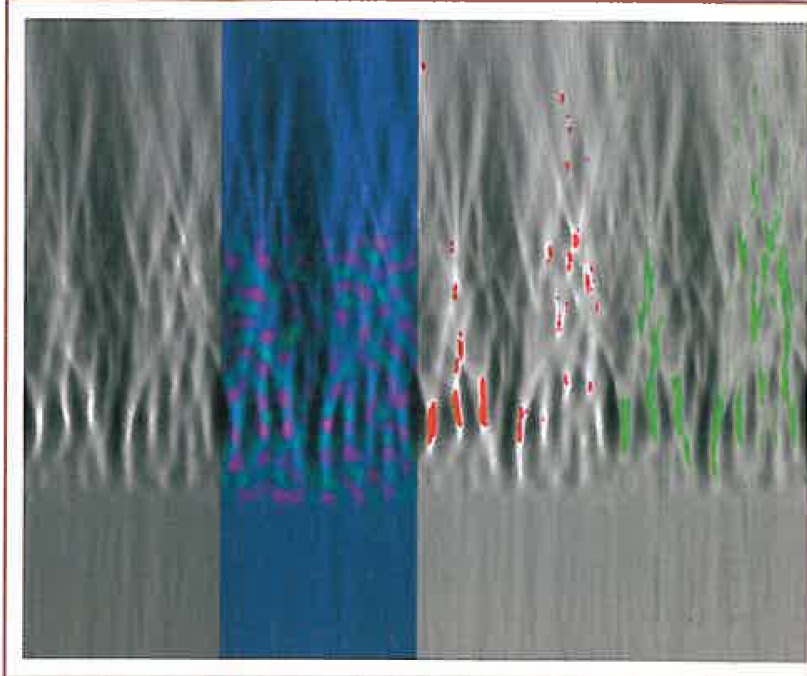

Fig. 4: This figure collects data from a long run with "Longuett-Higgins" Gaussian seas impinging from below on an eddy field, here represented as a potential force field. In the left panel, the average energy density of the waves is plotted in grayscale, with lighter regions having higher energy density. The potential field (deflecting the rays) is shown as hills (green) and valleys (purple) in the next panel. Severe freak wave events (waves six or more standard deviations computed from the mean Gaussian) were recorded as red in the next panel; note that there are no events before the refraction starts and some after it has ended. Finally the $4.4 \sigma$ events are shown in green in the right panel; there are a few of these before the refraction but many more after it starts and beyond.

[2] M.S. Longuet-Higgins, "The Statistical Analysis of a Random, Moving Surface" Philosophical Transactions of the Royal Society of London. Series A, Mathematical and Physical Sciences, Vol. 249, No. 966. (Feb. 21, 1957), pp. 321-387.

[3] T.B. Benjamin, and J. E. Feir, J. Fluid Mech. 27, 417-430,(1967).

[4] M. Onorato, A.R. Osborne, M. Serio, and S. Bertoni, "Freak Waves in Random Oceanic Sea States" Phys. Rev. Lett. 86, P. 5831-5834, (2001).

[5] K. Trulsen, and K.B. Dysthe, "A modified nonlinear Schrödinger equation for broader bandwidth gravity waves on deep water", Wave Motion 24, 281-289 (1996).

[6] H. Peregrine, "Interaction of water waves and currents," Adv. Appl. Mech. 16 9-117 (1976).

[7] B. S. White and B. Fornberg, "On the chance of freak waves at sea", J. Fluid.. Mech, 355, p. 113-138 (1998); see also M. Gerber, "The interaction of deep water gravity waves and an annular current: linear theory", J. Fluid Mech. 248 153-172 (1993).

[8] M.A. Wolfson and S. Tomsovic, "On the stability of long-range sound propagation through a structured ocean," J. Acoust. Soc Am. 109 2693-2703 (2001).

[9] M.A. Topinka, B.J. LeRoy, R.M. Westervelt, S.E.J. Shaw, R. Fleischmann, E.J. Heller, K.D. Maranowski, A.C. Gossard. "Coherent Branched Flow In a Two-Dimensional Electron Gas" Nature, 410 183-6 (2001).

[10] K.B. Dythse, in "Rogue Waves 2000", proceedings of a workshop held in Brest, France, 29-30 November 2000, M. Olagnon and G.A. Athanassoulis, editors. Plouzané, France : Editions Ifremer, (2001).

[11] E. J. Heller, Freak ocean waves and refraction of Gaussian seas in Extreme Events in Nature and Society Sergio Albeverio, Volker Jentsch, Holger Kantz (eds.) Springer 2005.

\section{Is Science Education} \section{Relevant?}

\author{
Henrik Busch, \\ Department of Curriculum Research, The Danish University of \\ Education, Copenhagen.
}

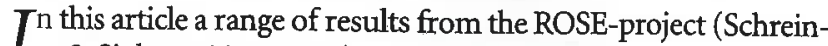
I er \& Sjøberg, 2004, 2005) are reported with particular focus on the question of whether science education is relevant to 15-year olds in three OECD countries: Japan, England and Denmark. Based on an analysis of the available data, four dimensions of science and science class relevance are investigated. These dimensions will be referred to as the Everyday life dimension, the Future- and career dimension, the Science, technology and society dimension and finally the Science class content dimension. Finally the results are discussed in a broader perspective.

Science education in Europe at all levels is facing significant challenges. Firstly; it is often argued that all citizens must be scientifically literate in order to participate competently in a modern knowledge-based society where science and technology have major impact on everybody's life. On a daily basis, we all face debates in media and in the political arena about socioscientific controversies such as global climate change, the use of gene manipulated organisms in food products and cloning of human beings (Kolstø, 2001). The need for a broadly based and competent participation in decision making concerning these issues demands of the educational system that science be taught in ways which make it interesting and relevant to all students (Andersen et al., 2003; Millar \& Osborne, 1998). Secondly, there is concern that European countries will find it increasingly more difficult to meet the need for a knowledge- and technologybased society to produce a high proportion of trained citizens capable of conducting research, development and education within science and technology (The High Level Group on Increasing Humans Resources for Science and Technology in Europe, 2004).

In order for European educational systems to meet these challenges science educators and scientists need a qualitatively deeper and more solid evidence-based understanding of young peoples' attitudes towards science, technology and school science. Hence the ROSE-project and this article.

\section{The ROSE-project}

The ROSE-project is an international comparative study led by Professor Svein Sjøberg along with Ph.D.-student Camilla Schreiner from the University of Oslo in collaboration with science education researchers from 40 other countries representing all continents except North America. In each country a geographically and socio-economically representative sample of 15year old students ${ }^{1}$ has filled out the ROSE-questionnaire, which consists of 250 statements (items) to which the students were asked to respond on a four-point Likert scale (see below). The complete international data set is not yet fully released, but for the purpose of the present article permission has been granted to publish some international results. 


\begin{tabular}{|c|c|c|c|c|c|c|c|}
\hline \multirow{2}{*}{$\begin{array}{l}\text { Item } \\
\text { F07 }\end{array}$} & \multirow{2}{*}{ Statement } & \multicolumn{3}{|c|}{ Mean } & \multicolumn{2}{|c|}{$\frac{\text { Mean difference }}{\text { G-B }}$} & \multirow{2}{*}{\begin{tabular}{|l|} 
Country \\
Japan \\
\end{tabular}} \\
\hline & & $\begin{array}{c}\text { Girls } \\
2.50\end{array}$ & $\frac{\text { Boys }}{2.70}$ & $\frac{\text { All }}{2.60}$ & -0.20 & Sig. & \\
\hline & & 2.71 & 2.68 & 2.68 & 0.03 & & England \\
\hline & & 2.35 & 2.37 & 2.37 & -0.02 & & Denmark \\
\hline & & 2.05 & 2.15 & 2.10 & -0.10 & & Denmark \\
\hline F10 & School science has increased my curiosity about things we cannot yet explain & 2.22 & 2.67 & 2.45 & -0.45 & Sig. & Japan \\
\hline & & 2.61 & 2.79 & 2.70 & -0.18 & Sig. & England \\
\hline & & 2.32 & 2.38 & 2.36 & -0.06 & & Denmark \\
\hline & & 2.33 & 2.24 & 2.29 & 0.09 & & Denmark \\
\hline F13 & School science has taught me how to take better care of my health & 1.96 & 2.18 & 2.07 & $-0 . \overline{22}$ & Sig. & Japan \\
\hline & & 2.68 & 2.60 & 2.64 & 0.08 & & England \\
\hline & & 2.34 & 2.24 & 2.30 & 0.10 & & Denmark \\
\hline
\end{tabular}

$\Delta$ Table 1: Student mean scores and gender differences for the five items defining the analytical dimension "Everyday life relevance of science classes"

International comparative studies represent a prominent trend in modern educational research. Within the field of science education, the TIMSS-studies (Trends in Mathematics and Science Studies) and lately the OECD PISA-studies (Programme for International Student Assessment) are the most elaborate, important and influential in terms of impact on educational policy. Broadly speaking, the aim of TIMSS is to assess to what extent (lower secondary school) students have achieved certain curricular goals within mathematics and science, whereas the PISA-studies attempt to obtain a measure of how well 15-years olds are able to handle challenges related to mathematics and science in a modern, complex and knowledge-based society. Both studies focus on cognitive factors, however, i.e. students' skills, competencies or level of scientific and mathematical literacy.

In contrast to these studies, the ROSE-project is focused on affective factors that influence students' participation in science classes and their current and future engagement in science and technology. ROSE is an acronym for Relevance Of Science Education and as indicated by the title, the aim is get insight into the perspective of learners on science, technology and science education. In most countries the science curriculum at all educational levels is uniquely defined by the proper authorities: legislative authorities, local boards at educational institutions and the teachers. There are, of course, good reasons for this. Society, the business world and the scientific communities have a range of legitimate interests in students acquiring particular skills and competencies. Until recently, however, we have failed to acknowledge and attempt to map thoroughly the learners' attitudes towards their science classes and towards science and technology in general. At least two reasons to do so can be mentioned. Firstly, we want to teach (science) for citizenship and thus put an emphasis on rational arguments, debate and consensus-making. This can only be done if we also acknowledge the learner's perspective and voice in a particular teaching situation. Secondly, and more pragmatically, we know that a positive attitude towards the content and the activities in a teaching situation is a fundamental prerequisite for a particulars learner's cognitive yield.

A range of studies of students' attitudes towards science using different methodologies have been performed during the last decade or so. A thorough review of these studies can be found in (Osborne, 2003), in which a range of factors known to influence students' attitudes towards science are presented and discussed. It is also pointed out that "the concept of attitude towards science is somewhat nebulous, often poorly articulated and not well understood" (Osborne, 2003). Are we talking about the opinion of the value of science, the motivation or anxiety towards science, the enjoyment of science, etc? Also, which kind of expression of interest or attitude are we dealing with? Is it expressed by a concrete action or a choice which significantly affects the individual's life (such as the choice of study at the tertiary level of education) or is it merely an expression free of responsibility, e.g. in a questionnaire?

In this article the focus will be on different dimensions of relevance of science classes in lower secondary school as seen from the perspective of 15-year olds and expressed as a degree of agreement upon a range of statements featured in the ROSEquestionnaire.

\section{The ROSE questionnaire}

The background for the ROSE-study, the objectives, the process of developing the questionnaire and thorough methodological discussions are presented in the background report for the project (Schreiner \& Sjøberg, 2004). In the present article a few key elements concerning the questionnaire are presented, whereas the reader is referred to the background document for further details.

The ROSE-questionnaire covers the following sections of items (the number in parenthesis refers to the number of 
questionnaire items belonging to a particular section) in addition to background information about the respondents:

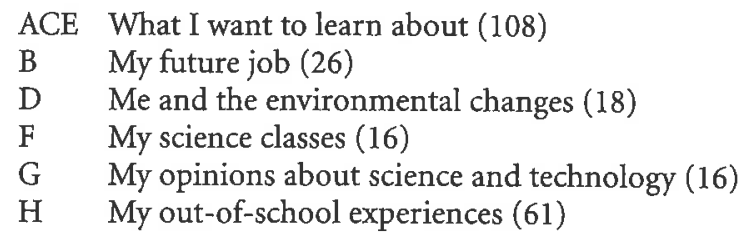

Examples of items from the questionnaire cover: "Stars, planets and the universe" (in the ACE section), where students must rate the statement on a four-point scale from "Not interested" to "Very interested", "School science is rather easy for me to learn" (in the F-sections), which is rated from "Disagree" to "Agree" and "Visited a science centre or science museum" (Hsection) to be rated from "Never" to "Often".

\section{Four dimensions of relevance}

"Relevance" is the key word in the ROSE-study. Most dictionaries will tell you that the definition of something being relevant involves being valuable and useful to people in their lives and work. However, you have to add the questions "Relevant to whom?" and "Relevant in which contexts?" Both questions are central within the ROSE-framework. The objective of ROSE is thus to investigate in which sense and in which contexts, science, technology and science education are perceived as valuable and useful to the learners (students) in their lives and work.

In this article four dimensions of relevance of science in school are investigated by analysing student responses from the Japanese, English and Danish samples. The question of students' attitudes towards science is thus for the present purpose narrowed down to being a matter of how and to what extent science as it is taught in schools might be valuable and useful. The question is attempted answered by analysing 15-year olds' own ex- pressions on these matters in the ROSE-questionnaire.

These four analytical dimensions are defined by items in the F-, G- and ACE-sections as follows:

Dimension 1: The 'everyday life' dimension

To what extent is school science valuable and useful to the students in their current everyday life outside school? Five items from the F-section are taken to define this analytic dimension. The statements of these items are presented in table 1. Notice that no specific field (e.g. physics, geosciences, biochemistry...) within science is mentioned in any statements among the $\mathrm{F}$ items. The assumption is that students implicitly will associate the statement with the science-related subjects they are being taught at the time of the filling in of the ROSE-questionnaire.

Dimension 2: The 'future and career' dimension

To what extent is school science valuable and useful to students in terms of preparing for a future career within the field of science and technology and for creating a desire to make a career within this field? The respondents' expressions of agreement to the statements shown in table 2 will be taken as a measure of this dimension.

Dimension 3: The 'science, technology and society' dimension School science might also be perceived as relevant by students in the sense that they recognize science and technology as important for the development of society and for improving living conditions for human beings. Five items from the G-section constitute this dimension of relevance of school science and are presented in table 3.

Dimension 4: The 'science class content' dimension It is known from earlier studies that the subject content taught in science classes is of crucial importance concerning the relevance of the teaching situation as seen from the learners' perspectives. The ROSE-questionnaire contains 108 items of the type "I would like to learn about..." followed by a science-related topic such as "Light around us that we cannot see", "Cloning of animals" and "Epidemics, diseases causing large

\begin{tabular}{|c|c|c|c|c|c|c|c|}
\hline \multirow{3}{*}{\begin{tabular}{|c|} 
Item \\
\\
F04 \\
\end{tabular}} & \multirow{3}{*}{$\begin{array}{l}\text { Statement } \\
\text { s to new and exciting jobs }\end{array}$} & \multicolumn{3}{|c|}{ Mean } & \multirow{2}{*}{\multicolumn{2}{|c|}{$\begin{array}{c}\text { Mean difference } \\
\text { G-B }\end{array}$}} & \multirow{3}{*}{\begin{tabular}{|l|} 
Country \\
\\
Japan \\
\end{tabular}} \\
\hline & & \multirow{2}{*}{$\frac{\text { Girls }}{2.05}$} & \multirow{2}{*}{\begin{tabular}{|c|} 
Boys \\
2.39 \\
\end{tabular}} & \multirow{2}{*}{\begin{tabular}{|c|} 
All \\
2.22 \\
\end{tabular}} & & & \\
\hline & & & & & -0.34 & Sig. & \\
\hline & & 2.00 & 2.29 & 2.14 & -0.29 & Sig. & England \\
\hline & & 1.81 & 2.18 & 1.99 & -0.37 & Sig. & Denmark \\
\hline F08 & I think that the science I learn at school will improve my career chances & 2.13 & 2.51 & 2.33 & -0.38 & Sig. & Japan \\
\hline & & 2.73 & 2.99 & 2.85 & -0.26 & Sig. & England \\
\hline & & 2.06 & 2.29 & 2.17 & -0.23 & Sig. & Denmark \\
\hline F14 & I would like to become a scientist & 1.29 & 1.82 & 1.56 & -0.53 & Sig. & Japan \\
\hline & & 1.54 & 1.88 & 1.70 & -0.34 & Sig. & England \\
\hline & & 1.39 & 1.75 & 1.56 & -0.36 & Sig. & Denmark \\
\hline F15 & I would like to have as much science as possible at school & 1.75 & 2.18 & 1.97 & -0.43 & Sig. & Japan \\
\hline & & 1.76 & 2.09 & 1.92 & -0.33 & Sig. & England \\
\hline & & 1.62 & 1.90 & 1.75 & -0.28 & Sig. & Denmark \\
\hline F16 & I would like to get a job in technology & 1.35 & 1.99 & 1.68 & -0.64 & Sig. & Japan \\
\hline & & 1.66 & 2.46 & 2.04 & -0.80 & Sig. & England \\
\hline & & 1.46 & 2.42 & 1.92 & -0.96 & Sig. & Denmark \\
\hline
\end{tabular}

A Table 2: Student mean scores and gender differences for the five items defining the analytical dimension "Future and career" 


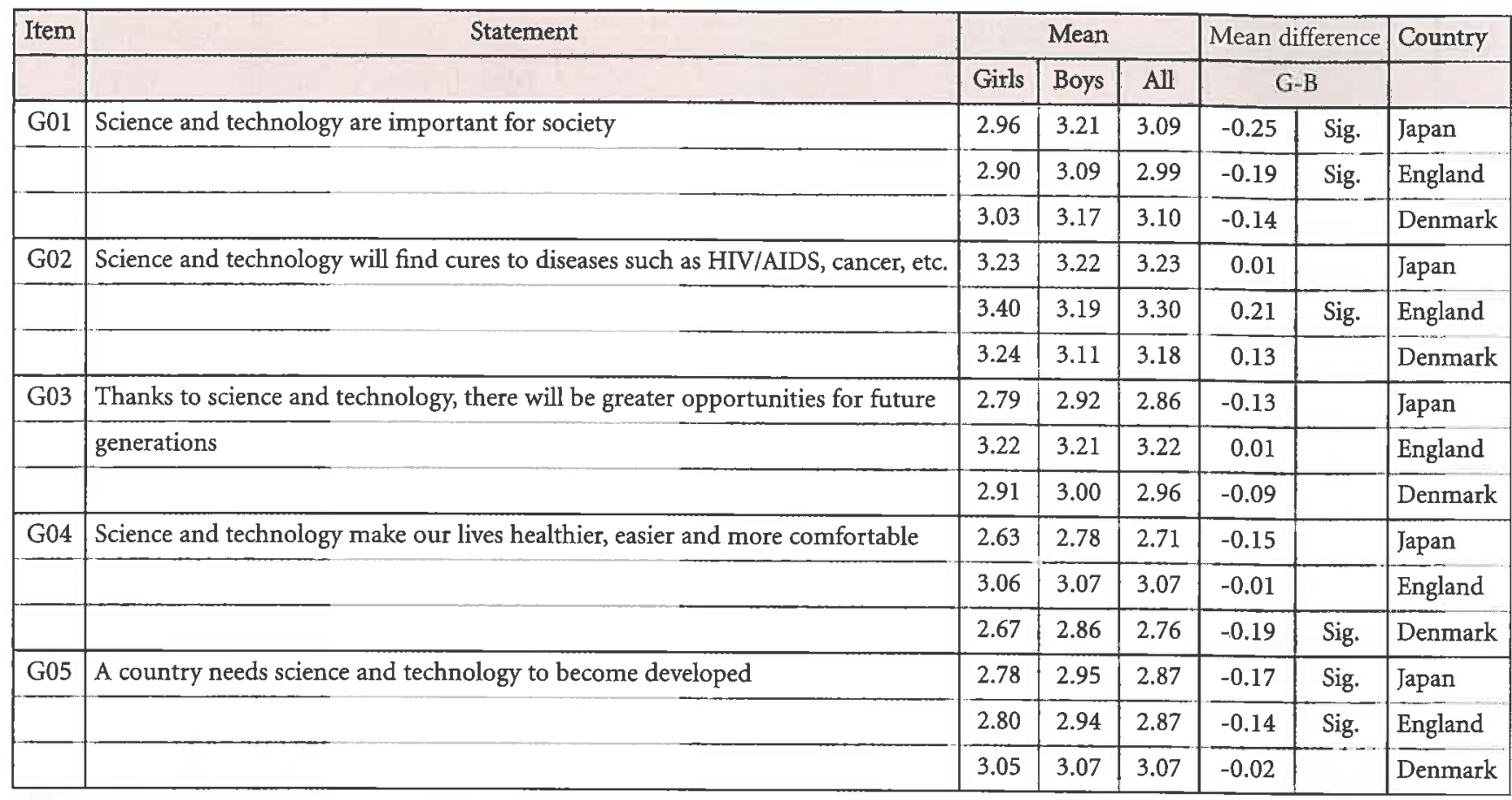

$\triangle$ Table 3: Student mean scores and gender differences for five items defining the analytical dimension "Science, technology and society".

loss of life". An analysis of the responses to these 108 items will show which topics would make science classes more relevant to the students, with regard to the content being taught.

\section{Results}

In order to reduce the complexity of the data, a coding of the responses with the assumption of a linear scale is adopted in the present analysis of student responses. The mean score of a particular item is thus calculated by assigning scores $(1,2,3,4)$ to responses in the four categories ranging from "Disagree" to "Agree" (in the case of e.g. F- and G-items). This representation of data simplifies the initial analysis and leads to some general conclusions concerning the four above-mentioned relevance dimensions.

In tables 1-3 the means for the item groups defining the relevance dimensions 1-3 are calculated for the respondents from the Japanese, English and Danish national samples. The means are shown for girls, boys and for all respondents in the national samples. The sample sizes are 560, 1266 and 538 for Japan, England and Denmark. In addition the gender difference defined as Mean(girls)-Mean(boys) is shown as well as a note of whether this difference is statistically significant ('Sig.') for the specific samples size as indicated by a two sample $t$ test with a $95 \%$ confidence interval. With the applied linear scale a mean score of 2.5 for a particular item is to be considered neutral and indicating neither noteworthy positive nor negative mean attitude towards the corresponding statement.

Table 1 shows that the perceived relevance in the everyday perspective is generally below the neutral line for the Danish students and with no significant gender differences on any items. For the Japanese and English samples, two and three items respectively, score above 2.5 , while two items score below. The item F07 scores relatively highly for all three samples, while the item F09 scores low. The latter item reflects a key element in many science curricula: the aim to foster the critical ability. The Japanese sample features significant gender differences for four items. The overall conclusion is that science classes in Japan and England are not overwhelmingly relevant to students seen from the 'everyday life' perspective, while they seem to be of even less relevance in Denmark.

The results from responses concerning the "Future and career" dimension are thought-provoking. Firstly, the mean values for the national samples are significantly below 2.5 for all items with F08 in England as the only exception. Somehow British schools seem to be good at communicating the message to the pupils that science can improve career chances, while this is apparently far from the case in Denmark and Japan; especially concerning the girls. Secondly they are strong gender differences for all items in all three samples, indicating that the future and career aspect of science classes is much weaker for

\begin{tabular}{|l|c|c|c|c|}
\hline \multicolumn{5}{|c|}{ F16. I would like to get a job in technology } \\
\hline & Disagree & & & Agree \\
\hline Girls & & 19 & 3 & 3 \\
\hline$>$ Japan & 75 & 27 & 13 & 4 \\
\hline$>$ England & 56 & 24 & 7 & 3 \\
\hline$>$ Denmark & 67 & & & \\
\hline Boys & & 26 & 19 & 12 \\
\hline$>$ Japan & 43 & 24 & 28 & 21 \\
\hline$>$ England & 26 & 29 & 28 & 19 \\
\hline$>$ Denmark & 24 & & & \\
\hline
\end{tabular}

$\Delta$ Table 4: Frequency table (percentages) showing student responses to the statement "I would like to get a job in technology" 


\begin{tabular}{|c|l|c|c|c|c|c|}
\hline Item & \multicolumn{1}{|c|}{ Statement } & \multicolumn{3}{c|}{ Mean } & \multicolumn{2}{c|}{ Mean difference } \\
\hline & \multicolumn{1}{|c|}{ Girls } & Boys & All & \multicolumn{2}{c|}{ G-B } \\
\hline C13 & Why we dream while we are sleeping, and what the dreams may mean & 3.34 & 2.34 & 2.85 & 1.00 & Sig. \\
\hline A40 & How to exercise to keep the body fit and strong & 3.24 & 2.74 & 2.99 & 0.50 & Sig. \\
\hline E11 & What we know about HIV/AIDS and how to control it & 3.20 & 2.58 & 2.90 & 0.62 & Sig. \\
\hline E13 & How different narcotics might affect the body & 3.18 & 2.65 & 2.93 & 0.53 & Sig. \\
\hline E09 & Sexually transmitted diseases and how to be protected against them & 3.16 & 2.66 & 2.91 & 0.50 & Sig. \\
\hline E12 & How alcohol and tobacco might affect the body & 3.14 & 2.68 & 2.92 & 0.46 & Sig. \\
\hline E08 & Cancer, what we know and how we can treat it & 3.12 & 2.60 & 2.87 & 0.52 & Sig. \\
\hline E10 & How to perform first-aid and use basic medical equipment & 3.12 & 2.70 & 2.92 & 0.42 & Sig. \\
\hline A37 & What to eat to keep healthy and fit & 3.11 & 2.35 & 2.73 & 0.76 & Sig. \\
\hline A38 & Eating disorders like anorexia or bulimia & 3.03 & 1.81 & 2.43 & 1.22 & Sig. \\
\hline
\end{tabular}

$\triangle$ Table 5a: Mean scores for the 10 highest scoring items among Danish girls in the ACE-section:"What I would like to learn about".

the girls. Danish boys and girls score lower on all items compared with the English and Japanese students, with the item (F16) concerning 'getting a job in technology' as the only exception (and F14 for the girls). The distribution of responses for F16 is shown in table 4 in which the large gender difference is even more striking. Roughly $60-75 \%$ of the girls completely reject the thought of making a career in technology. Only in England does the percentage of girls expressing any wish to work in this field exceed $10 \%$. With respect to the boys, Japan seems to have a particular problem, since close to $70 \%$ generally disagree with the statement. The conclusion from this analysis is that with respect to the 'future and career' perspective, science classes in the three countries seem to be of little value in particular to girls and to the Danish boys.

In table 3 the mean values for the five items of the 'Science, technology and society' dimension are listed. The first thing to notice is that mean values in general are well above 2.5 indicating an overall large degree of acknowledgement of the importance of science and technology in creating better living conditions in the future and in general in enabling the development of societies. There is an especially strong belief in the potential for finding methods for curing diseases (G02), in particular among girls. Apart from this item, girls generally score lower on these items than boys, though the differences are far from the level featured in table 2.

Finally, table 5a and 5b give an example of how the value of science lessons may differ for groupings of students depending on the subject content taught in a specific class. The table shows the ten highest scoring items, for Danish girls and boys respectively, among the $108 \mathrm{ACE}$-items with the heading "What I would like to learn about". It is worth pointing out that girls' mean scores in table $5 \mathrm{a}$ are very high - indicating a strong agreement between the girls that these subjects are interesting. Also, the very large gender differences for these 10 items should be pointed out. Girls' interests seem to be focused on health, medicine, body and themes related to themselves. The corresponding table for the boys features mean values that are somewhat lower than observed for the girls and gender differences which are more varied. For seven of the items, the boys' mean scores are significantly higher than the girls' score, but when it comes to learning about life outside the earth and feeling weightless, no difference can be shown. There is even one item
("How to exercise to keep fit and strong") on the boys' top 10 list, for which the girls' score is higher. The boys' responses indicate a wish to learn about the dramatic and violent aspects of physics and chemistry and about how technology works. Finally it should be mentioned that Jenkins (Jenkins \& Nelson, 2005) has published a range of analyses based on the English ROSE-data and includes the English "Top-10 lists" corresponding to table $5 \mathrm{a}$ and $5 \mathrm{~b}$. There is a striking resemblance between the two sets of lists with eight of ten possible overlapping items for the girls and six of ten overlapping items for the boys. More results from the national Japanese ROSE-study can be found in (Ogawa, 2004), whereas a range of analyses of Danish results is available on the homepage for the Danish ROSEproject: www.dpu.dk/rose.

\section{Discussion}

The results of the analysis presented in this article are very well summarized by the title of the recent paper by the English ROSE-team (Jenkins \& Nelson, 2005) "Important but not for me: students' attitudes towards secondary school science in England". We have shown that English, Japanese and Danish 15 -years olds find school science only moderately relevant from an everyday perspective and of little value from a 'future and career' point of view. The last conclusion is especially pronounced for girls in all three countries and for Japanese boys as well. On the other hand, there is a clear acknowledgement of the benefits of science and technology for society and for the individual in terms of development, finding cures for diseases and creating better living conditions in general.

Summing up, there seems to be an understanding among young people of the fact that knowledge- and technology-based societies need more scientists, but at the same time a lack of will and motivation to devote one's own working life to support this development. In (Schreiner \& Sjøberg, 2005) a preliminary international comparative analysis including all ROSE-countries has been presented. It is clear from this work that (generally speaking) northern European countries and Japan, followed by Eastern and Southern European countries tend to score lowest on the three 'relevance' dimensions presented in tables 1-3. At the other end of the scale, African countries (from mainly south of the Sahara) score very high and are followed by the participating Asian countries with only somewhat lower scores. 


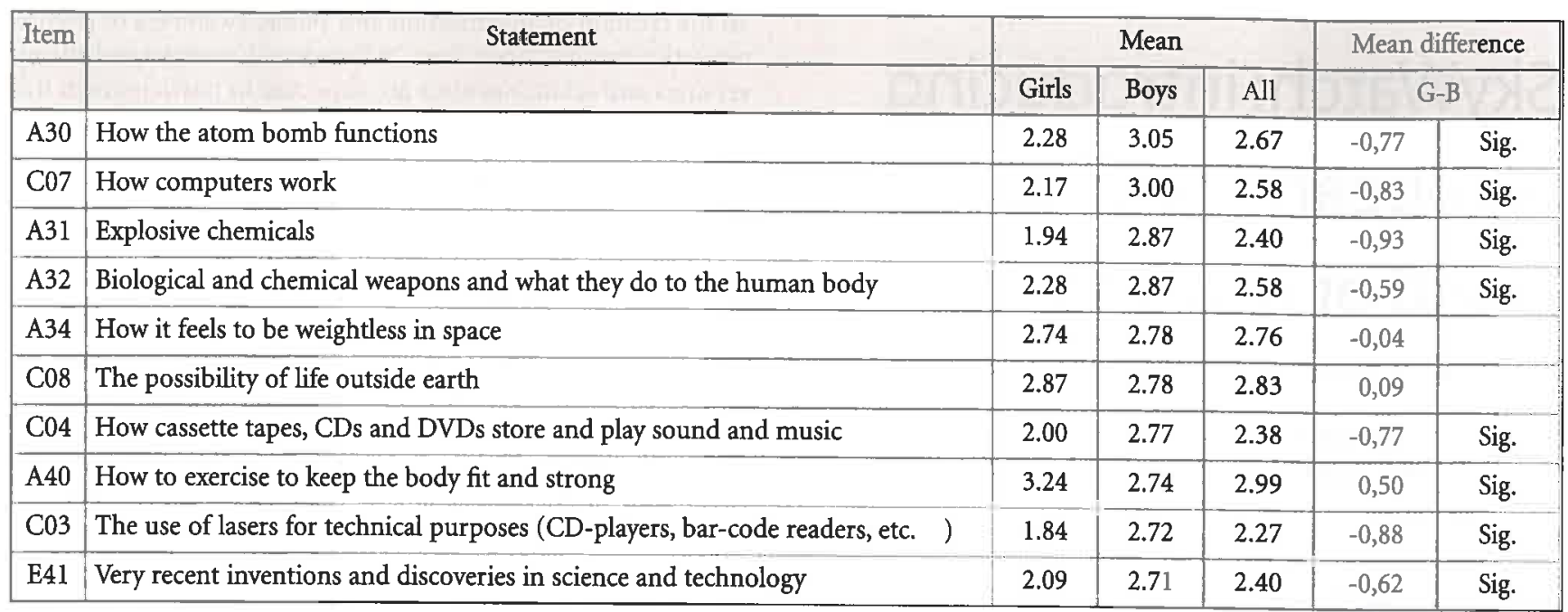

A Table 5 b: Mean scores for the 10 highest scoring items among Danish boys in the ACE-section: "What I would like to learn about".

It is important to develop a better understanding of the reasons for the "Science is important but not for me"-attitude in order to secure a high level of scientific literacy in the population and to increase recruitment to science and technology studies. An understanding of the (post-)modern society, of the youth cultures created by this society and of the latent attitudes towards science within these cultures is a prerequisite in order to make the changes necessary in school science. The ROSEstudy will produce the evidence-based characteristics of these attitudes, which, combined with proper sociological theories, will hopefully provide us with the necessary qualitative understanding.

\section{About the Author}

With a Ph.d. in physics from the Niels Bohr Institute, Henrik Busch moved in 1998 from the field of research in nanoscience in to research in science education. He is currently an associate professor at The Danish University of Education in Copenhagen. Lately has has co-authored the strategy plan for science education on behalf of the Danish Ministry of Education, he is chief-editor of the first Danish research-based journal of mathematics- and science education and he is the leader of the Danish ROSE-project.

\section{Acknowledgements}

The author would like to thank Professor Svein Sjøberg from the University of Oslo, Professor Edgar Jenkins from the University of Leeds and Professor Masakata Ogawa from Kobe University for admitting the use of previously unpublished data in this article. The Danish ROSE-project is financed by grants from The National Education Authority at The Danish Ministry of Education and from The Danish University of Education.

\section{References}

Andersen, N., Busch, H., Horst, S., \& Troelsen, R. (Eds.). (2003). Fremtidens naturfaglige uddannelser. Naturfag for alle - vision og oplæg til strategi (Vol. 7). København: Undervisningsministeriet, Uddannelsesstyrelsen. (In Danish, but with an English summary)

Jenkins, E. W., \& Nelson, N. W. (2005). Important but not for me: Students' attitudes towards secondary school science in England. Research in Science and Technological Education, 23(1).
Kolstø, S. D. (2001). Scientific literacy for citizenship: Tools for dealing with the science dimension of controversial socioscientific issues. Science Education, 85, 291-310.

Millar, R., \& Osborne, J. (Eds.). (1998). Beyond 2000: Nuffield Foundation.

Ogawa, M. (2004). Three Distinctive Groups among Japanese Students in terms of their School Science Preference: From Preliminary Analysis of Japanese Data of an International Survey 'The Relevance of Science Education' (ROSE).

Journal of Science Education in Japan, 28(4), 279-291."

Osborne, J. (2003). Attitudes towards science: A review of literature and its implications. International Journal of Science Education, 25(9), 1040-1079.

Schreiner, C., \& Sjøberg, S. (2004). Rose - the relevance of science education (No. 4/2004). Oslo: ILS (www.ils.uio.no/forskning/rose/)

Schreiner, C., \& Sjøberg, S. (2005). Harvesting the bouquets of rose (2) diagrams with national mean scores for girls and boys in questions $\mathrm{b}, \mathrm{d}, \mathrm{f}$ and $\mathrm{g}$ in the rose questionnaire. Oslo: ILS (www.ils.uio.no/forskning/rose/)

The High Level Group on Increasing Humans Resources for Science and Technology in Europe. (2004). Europe needs more scientists increasing human resources for science and technology in europe: European Commission - Directorate C: Science and Society.

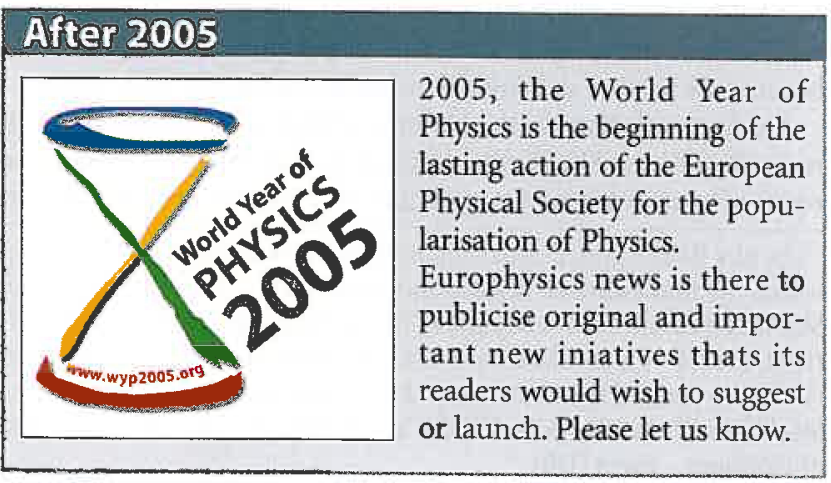

